Discussion Paper No. 07-026

\title{
Macroeconomic Impacts of the Clean Development Mechanism: The Role of Investment Barriers and Regulations
}

Niels Anger, Christoph Böhringer, and Ulf Moslener

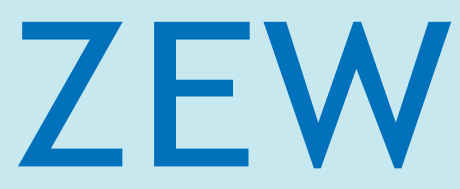

Zentrum für Europäische Wirtschaftsforschung $\mathrm{GmbH}$

Centre for European

Economic Research 
Discussion Paper No. 07-026

\section{Macroeconomic Impacts of the Clean Development Mechanism: The Role of Investment Barriers and Regulations}

Niels Anger, Christoph Böhringer, and Ulf Moslener

Download this ZEW Discussion Paper from our ftp server:

ftp://ftp.zew.de/pub/zew-docs/dp/dp07026.pdf

Die Discussion Papers dienen einer möglichst schnellen Verbreitung von neueren Forschungsarbeiten des ZEW. Die Beiträge liegen in alleiniger Verantwortung der Autoren und stellen nicht notwendigerweise die Meinung des ZEW dar.

Discussion Papers are intended to make results of ZEW research promptly available to other economists in order to encourage discussion and suggestions for revisions. The authors are solely responsible for the contents which do not necessarily represent the opinion of the ZEW. 


\section{Non-Technical Summary}

Under the Kyoto Protocol, industrialized countries have committed to legally binding emissions targets to be achieved during 2008 to 2012. To fulfil these commitments, the protocol allows for three flexible mechanisms: Besides International Emissions Trading, industrialized countries may generate emissions credits through project-based reductions. This can be done by investing in other industrialized regions in terms of Joint Implementation (JI) as well as in developing countries via the Clean Development Mechanism (CDM). The prospect of large CDM potentials at low cost in developing countries has attracted the attention by industrialized countries. However, the attractiveness of the project-based mechanisms may be substantially diminished by investment barriers and environmental regulation of the CDM.

This study quantifies the macroeconomic impacts of the Clean Development Mechanism under the Kyoto Protocol taking into account investment barriers such as transaction costs and investment risks in the host country. Moreover, we assess institutional constraints of CDM investment such as supplementarity and additionality regulations. For our quantitative analysis we employ a large-scale computable general equilibrium model of international trade and global energy use, integrating explicit project-based bottom-up CDM supply curves into our top-down macroeconomic model framework.

We find that the CDM is an important flexibility mechanism to achieve the Kyoto targets at low cost - in particular, if industrialized countries intend to exclude Russian excess emissions permits (so-called "hot air") from international emissions trading. The main driver of this result is the availability of large amounts of CDM credits at very low cost. The inclusion of risk and transaction costs increases the international carbon price by typically less than 1 US\$ per ton of carbon dioxide. Thus they play an inferior role for the overall compliance costs. Much more relevant are policy constraints to using the CDM as reflected by additionality or supplementarity criteria, both inducing higher levels of domestic emissions abatement. While project-based emissions crediting clearly should generate emissions reductions in addition to those that would have occurred in the absence of the CDM, from a pure cost-effectiveness perspective our simulation analysis suggests caution against restrictive regulations of CDM access by means of a supplementarity rule. 


\title{
Macroeconomic Impacts of the Clean Development Mechanism: The Role of Investment Barriers and Regulations
}

\author{
Niels Anger ${ }^{\mathrm{a}}$, Christoph Böhringer ${ }^{\mathrm{a}, \mathrm{b}}$, Ulf Moslener ${ }^{\mathrm{a}}$ \\ ${ }^{a}$ Centre for European Economic Research (ZEW), P.O. Box 103443, 68034 Mannheim, Germany \\ ${ }^{\mathrm{b} U n i v e r s i t y ~ o f ~ O l d e n b u r g, ~ D e p a r t m e n t ~ o f ~ E c o n o m i c s, ~} 26111$ Oldenburg, Germany \\ E-mails: anger@zew.de, christoph.boehringer@uni-oldenburg.de, moslener@zew.de
}

\begin{abstract}
This paper quantifies the macroeconomic impacts of the Clean Development Mechanism (CDM) under the Kyoto Protocol based on a computable general equilibrium (CGE) model of international trade and energy use. Employing project-based CDM supply data we assess the relative importance of transaction costs and investment risks as well as CDM regulations through supplementarity and additionality criteria. Our numerical results show that the macroeconomic impacts of transaction costs and investment risks are negligible: Given the large supply of cheap project-based emissions credits in developing countries, compliance to the Kyoto Protocol can be achieved at a very low cost. However, regulatory restrictions such as a supplementarity criterion can substantially curtail the potential efficiency gains from where-flexibility in climate policy.
\end{abstract}

JEL classification: C68, D61, Q56, Q58

Keywords: Kyoto Protocol, Emissions Trading, Clean Development Mechanism, Computable General Equilibrium

Acknowledgements: Funding by the European Commission under the $6^{\text {th }}$ Framework programme regarding the research project "Technology Transfer and Investment Risk in International Emissions Trading” (TETRIS) is gratefully acknowledged. 


\section{Introduction}

Under the Kyoto Protocol, industrialized countries as listed in Annex B of the agreement have committed to legally binding emissions targets to be achieved during 2008 to 2012. For these commitments to be fulfilled economically, the protocol allows for three flexible mechanisms: Besides international emissions trading, industrialized countries may undertake emissions crediting through project-based reductions - both in Annex B regions in terms of Joint Implementation (JI) as well as in developing countries in terms of the Clean Development Mechanism (CDM). Imports of JI and CDM credits, i.e. Emissions Reduction Units (ERUs) and Certified Emissions Reductions (CERs), can thereby serve as substitutes for both domestic abatement action and international emissions trading.

Given the prospects of larger CDM potentials at low cost in developing countries, CDM investments have attracted the attention by industrialized countries for meeting their emissions targets under the Kyoto Protocol. Despite their potential for cost-efficient emissions abatement, the attractiveness of the project-based mechanisms may be substantially lowered by transaction costs arising from implementation procedures and bureaucracy (Jotzo and Michaelowa, 2002). Moreover, there can be larger risks associated with investments in CDM projects: If the economic or political stability in developing countries is weak, uncertainty about the effective crediting of envisaged emissions reductions might be high (Oleschak and Springer, 2007).

Beyond considerations of transaction costs and investment risks, additional policy-driven regulations could substantially reduce the attractiveness of the CDM. The Marrakech Accords to the Kyoto Protocol demand that domestic emissions abatement (as opposed to the use of flexibility mechanisms) constitutes a "significant element" of the efforts made by each Annex B region to meet its target under the Kyoto Protocol (UNFCCC, 2002). Vice versa, the flexible mechanisms shall only be supplemental to domestic action. The limits to CER imports imposed by such a supplementarity rule could substantially curtail the potential costsavings from project-based crediting. Moreover, the Marrakech Accords require additionality of CDM projects: Abatement that would have also occurred in the absence of the registered CDM project activity in the developing region has to be excluded.

In this paper we quantify the macroeconomic impacts of the Clean Development Mechanism under the Kyoto Protocol taking into account transaction costs and investment risks as well as supplementarity and additionality regulations. For our quantitative analysis we employ a large-scale computable general equilibrium model of international trade and global energy 
use. Our numerical results suggest that a large supply of cheap CDM options - together with rather small effective emissions reduction requirements of Annex B countries - imply very low compliance cost of the Kyoto Protocol. Moreover, transaction costs and investment risks play a negligible role while regulatory CDM restrictions - associated with additionality and supplementarity of the CDM - induce some (limited) increase of the permit price and economy-wide adjustment costs.

The economic impacts of the flexible mechanisms under the Kyoto Protocol have been assessed in several quantitative studies. Weyant and Hill (1999) provide a multi-model evaluation which confirms larger cost savings from where-flexibility based on global emissions trading. Böhringer and Löschel (2002) employ a partial equilibrium model to analyze the implications of investment risks for the magnitude and regional distribution of efficiency gains from project-based emissions crediting. Michaelowa and Jotzo (2005) assess the role of transaction costs and institutional rigidities for the market size of the CDM likewise building on a numerical partial equilibrium approach. All of these studies focus on an implicit, top-down representation of CDM market supply.

The contribution of our paper to the literature is twofold: Firstly, we integrate explicit projectbased bottom-up CDM supply curves into a top-down macroeconomic model framework. Secondly, we deliver a more comprehensive integrated analysis of the multiple determinants of potential CDM efficiency gains (i.e. investment risks and transaction costs as well as supplementarity and additionality restrictions).

The remainder of the paper is organized as follows. In section 2, we briefly describe our numerical framework. In section 3, we lay out the climate policy scenarios underlying our simulation analysis. In section 4 , we present quantitative results. In section 5 , we conclude.

\section{Analytical Framework}

\subsection{Non-technical Model Summary}

For our simulation analysis we use a standard computable general equilibrium (CGE) model of international trade and global energy use. CGE models have become the standard tool for economy-wide impact assessment of environmental policies (for surveys on applications to environmental policies see Conrad 1999, 2001) as they provide a comprehensive representation of price-dependent market interactions based on microeconomic theory. The 
simultaneous explanation of the origin and spending of agents' incomes makes it possible to address both economy-wide efficiency as well as distributional impacts of policy interference. A central extension of the standard CGE framework for our analysis concerns the integration of bottom-up CDM supply curves for developing countries featuring specific transaction cost and investment risk aspects. Our extension builds on the availability of appropriate data which is described in section 2.2. In the following, we restrict ourselves to a short nontechnical summary of the CGE model underlying our numerical analysis. Details on the basic model algebra and parameterization are available in Böhringer (2000, 2002) or Böhringer and Vogt (2003, 2004).

Figure 1 provides a diagrammatic structure of the generic open-economy model. A representative agent $R A_{r}$ in each region $r$ is endowed with three primary factors: labor $\bar{L}_{r}$, capital $\bar{K}_{r}$, and fossil-fuel resources $\bar{Q}_{f f, r}$ (used for fossil fuel production). The representative agent maximizes utility from consumption of a composite good $C_{r}$ which combines demands for energy and non-energy commodities at a constant-elasticity-of-substitution (CES). Production $Y_{\text {ir }}$ of commodities $i$ in region $r$ is captured by nested separable CES functions that describe the price-dependent use of capital, labor, energy and material in production. Carbon emissions are linked in fixed proportions to the emission-relevant use of fossil fuels with carbon coefficients differentiated by the specific carbon content of fuels. Carbon abatement can take place by fuel switching or energy savings in production and final consumption.

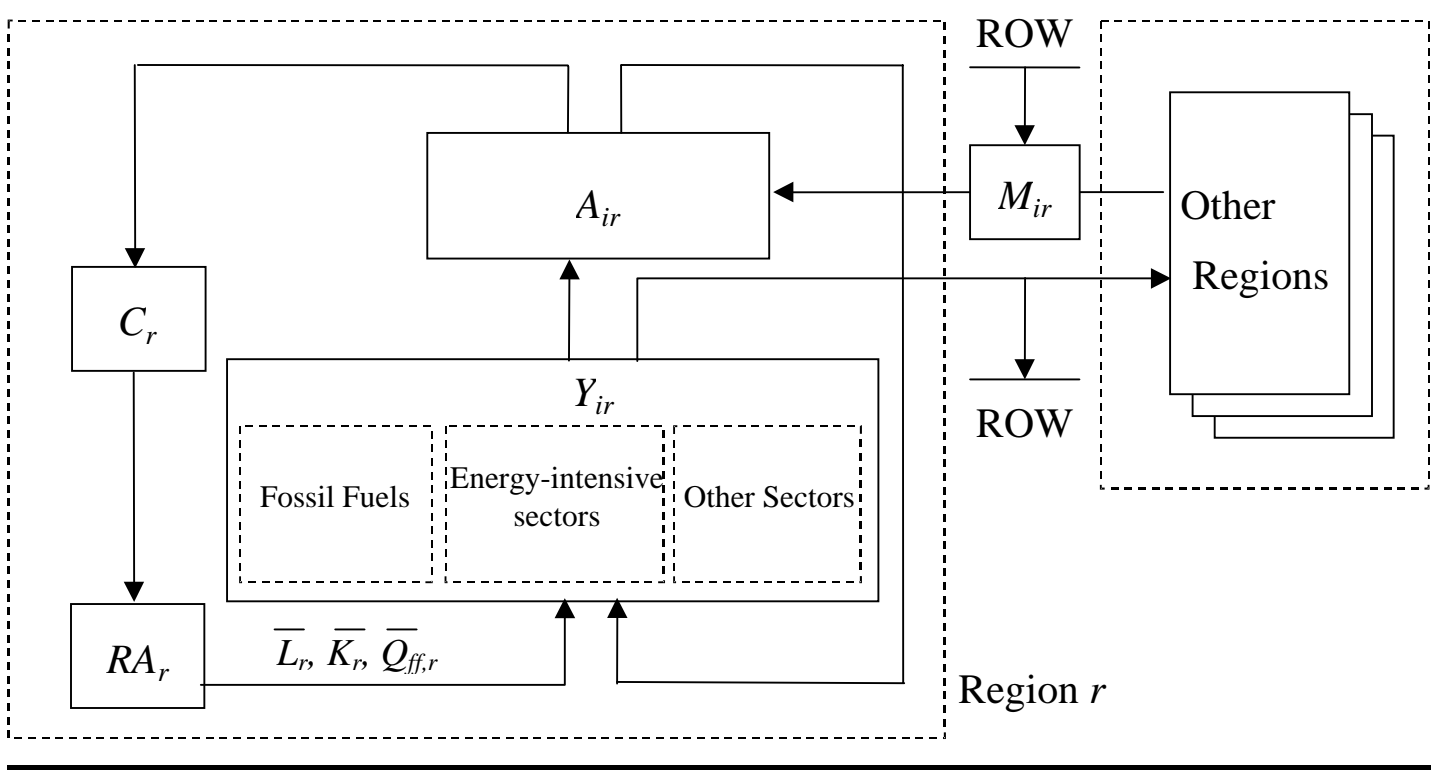

Figure 1: Diagrammatic overview of the model structure 
Trade is specified following the Armington approach of product heterogeneity (Armington, 1969), i.e., domestic and foreign goods of the same variety are distinguished by origin. All goods used on the domestic market in intermediate and final demand correspond to a CES composite $A_{i r}$ that combines the domestically produced variety $Y_{i r}$ and imports $M_{i r}$ of the same variety from other regions. Domestic production $Y_{i r}$ either enters the formation of the Armington good $A_{i r}$ or is exported to satisfy the import demand of other regions. Trade with regions ROW (rest of the world) that are not explicitly represented in domestic production and consumption structures are described by a set of export demand and import supply functions. A balance of payment constraint, which is warranted through flexible exchange rates, incorporates the benchmark trade deficit or surplus between the explicit model regions and the rest of the world (ROW).

\subsection{Data and parameterization}

In this section we present the model calibration and the set of relevant inputs for our numerical analysis. These include project-based CDM supply curves, CDM transaction costs and investment risk indicators as well as emissions projections to 2010.

\section{Calibration}

The model is based on consistent accounts of national production and consumption, bilateral trade and energy flows for 2001 (as provided by the GTAP6 database - see Dimaranan and McDougall 2006). As is customary in applied general equilibrium analysis, the benchmark data for quantities and prices together with exogenous elasticities determine the free parameters of the functional forms.

In our comparative-static framework we infer the business-as-usual $(\mathrm{BaU})$ structure of the model's regions - i.e. the reference situation without exogenous emissions constraints - for 2010 using most recent projections on economic development. These include expert projections for GDP growth, energy demand, fuel mixes in electricity generation, and future energy prices. ${ }^{1}$ We thereby use official data on trends for EU Member States (European Commission, 2003) and for non-European economies (US Department of Energy, 2005). The effects of climate policy interference are then measured with respect to the benchmark, i.e. $\mathrm{BaU}$, situation where no carbon limits apply.

\footnotetext{
${ }^{1}$ See Böhringer, Jensen, and Rutherford (2000) for a detailed description of related calibration techniques.
} 
For our assessment of regional compliance costs to the Kyoto Protocol, we include all major Annex B regions that have ratified the agreement and therefore face legally binding emissions reduction commitments: EU Member States, Russia, the remaining Former Soviet Union, Japan and Canada. Besides international emissions trading among each other, these regions may undertake project-based emissions reductions in developing regions (representing CDM host countries). ${ }^{2}$ Table 1 gives an overview of the Annex $\mathrm{B}$ regions that are incorporated explicitly in our model together with six major developing regions whose CDM options are represented by discrete project-based supply functions (see the following section for more details).

Table 1: Model regions

\begin{tabular}{|l|c|}
\hline \multicolumn{1}{|c|}{ Model region } & Characteristics \\
\hline $\begin{array}{l}\text { EU-27 } \\
\text { Russian Federation } \\
\text { Rest of Former Soviet Union } \\
\text { Japan } \\
\text { Canada }\end{array}$ & $\begin{array}{c}\text { Annex B parties ratifying } \\
\text { the Kyoto Protocol }\end{array}$ \\
\hline $\begin{array}{l}\text { China incl. Hong Kong } \\
\text { India } \\
\text { Rest of East South Asia } \\
\text { Brazil } \\
\text { Central + South America } \\
\text { South Africa }\end{array}$ & \\
\hline
\end{tabular}

At the sectoral level the model incorporates details on differences in factor intensities, degrees of factor substitutability and price elasticities of output demand in order to trace back the structural change induced by carbon abatement policies. The sectors in the model have been carefully selected to keep the most carbon-intensive sectors in the available data as separate as possible.

The costs of complying with Kyoto crucially depend on the extent to which the emissions reduction commitments bind economies in the budget period between 2008 and 2012. The expected magnitude of abatement costs is directly linked to the structural characteristics of each particular economy exhibited in the $\mathrm{BaU}$ situation without exogenous emissions constraints. For example, higher economic growth in the baseline will - ceteris paribus -

\footnotetext{
${ }^{2}$ Note that - in our model framework - international emissions trading between Annex B parties includes JI.
} 
result in increased $\mathrm{BaU}$ emissions that imply higher compliance costs with the Kyoto targets. On the other hand, energy efficiency improvements allow decoupling economic growth from emissions increase. The specific differences in economic development may alter the crosscountry differences with respect to the effective reduction requirement under the Kyoto Protocol.

\section{Project-based CDM supply curves}

CDM supply curves for major host countries are explicitly implemented into the modelling framework based on detailed (bottom-up) information about project-specific abatement options. The discrete step functions for CDM supply are derived from a comprehensive database of greenhouse gas (GHG) reduction options elaborated by Wetzelaer et al. (2007). The CDM database was built through evaluation and aggregation of GHG emissions reduction studies and concrete (implemented) CDM projects in non-Annex B countries. It comprises information on the abatement potential and cost of greenhouse gas reduction options for 30 non-Annex B countries and in total 371 reduction options. The countryspecific data on abatement potential and abatement cost have been translated into step functions, relating marginal abatement costs to abatement potential. To ensure compatibility with the microeconomic paradigm of rational behaviour underlying our CGE model, so-called "No-regret" options - reported in the CDM database - are assumed to be available at zero cost (rather than at negative cost). We will discuss the corresponding CDM supply data in more detail further down.

\section{Transaction costs}

The potential benefits of project-based abatement measures may be substantially reduced by transaction costs associated with abatement projects in developing countries. Such transaction costs may arise from a variety of activities associated with market exchange, including search and information acquisition, negotiation, monitoring or enforcement of contracts.

In our bottom-up characterisation of CDM supply curves we incorporate estimates of projectbased transaction costs for CDM credits by Wetzelaer et al. (2007). Transaction cost enter our model as an absolute premium on marginal abatement costs of CDM host countries (typically 
ranging between 0.2 and $0.7 \mathrm{US} \$ / \mathrm{tCO}_{2}$ ) and thereby induce an upward shift of the CDM supply curve. ${ }^{3}$

\section{Investment risk}

Investment risk involved in financing carbon-abatement projects constitutes another important aspect for the appropriate assessment of efficiency gains from project-based emissions crediting under the Kyoto Protocol.

We adopt a composite indicator for CDM investment risks developed by Oleschak and Springer (2007). This indicator has been computed on the basis of a large pool of data for 143 countries, which were divided into industrialized countries and developing and transition countries (CDM host countries). The indicator builds on three components: the institutional environment for CDM activities, the regulatory environment, and the economic environment. Country-specific information pertaining to each component has been weighted and aggregated. The composite indicator ranks the countries according to the total risk of investing in GHG abatement projects. Table 2 presents the CDM-specific investment risk premia for key CDM host regions.

Table 2: CDM-specific investment risk premia for developing regions

\begin{tabular}{|l|r|}
\hline \multicolumn{1}{|c|}{ Region } & Risk premium (\%) \\
\hline Brazil & 4.6 \\
\hline China including Hong Kong & 1.8 \\
\hline Central and South America & 3.0 \\
\hline India & 1.8 \\
\hline Rest of East South Asia & 12.0 \\
\hline South Africa & 7.3 \\
\hline Rest of World & 16.0 \\
\hline
\end{tabular}

Source: Oleschak and Springer (2007)

Investment risks enter our numerical model as a relative discount on the CER price (in \%). Risk lowers the expected return of CDM projects and effectively induces an upward rotation of the CDM supply curve.

\footnotetext{
${ }^{3}$ An alternative approach to account for CDM transaction costs is presented by Kallbekken et al. (2006), who introduce a so-called "participation rate" reflecting that only some share of potentially profitable CDM projects will be implemented.
} 
Emissions projections for 2010

Owing to the critical role of baseline projections for the simulation results, we provide further details on country-specific emissions in 2010 (our reference year for compliance to the Kyoto Protocol) and the associated effective reduction requirements for Annex B countries. Furthermore, we present the CDM supply curves for major developing regions.

Table 3 summarizes baseline emissions for the years 1990 and 2010 across the Annex B countries explicitly incorporated in our model. The Kyoto reduction targets have been stated with respect to emissions levels in 1990 yielding implicit effective reduction requirements in 2010 which depend on the region-specific baseline (BaU) emissions. 
Table 3: Baseline emissions and reduction requirements of Annex-B countries

\begin{tabular}{|c|c|c|c|c|}
\hline & $\begin{array}{r}\text { Baseline CC } \\
\text { (Mt of }\end{array}$ & $\begin{array}{l}\text { nissions } \\
\text { 2) }\end{array}$ & $\begin{array}{c}\text { Kyoto } \\
\text { reduction } \\
\text { target }\end{array}$ & $\begin{array}{c}\text { Effective } \\
\text { reduction } \\
\text { requirement } \\
\text { (\% vs. }\end{array}$ \\
\hline Region & 1990 & 2010 & 2010 & 2010 \\
\hline Austria & 55.1 & 60.7 & 13.0 & 21.0 \\
\hline Belgium & 106.3 & 112.2 & 7.5 & 12.4 \\
\hline Denmark & 52.8 & 46.6 & 21.0 & 10.5 \\
\hline Finland & 53.2 & 51.4 & 0.0 & -3.5 \\
\hline France & 354.1 & 406.4 & 0.0 & 12.9 \\
\hline Germany & 943.0 & 823.6 & 21.0 & 9.5 \\
\hline UK & 569.1 & 519.4 & 12.5 & 4.1 \\
\hline Greece & 71.1 & 105.6 & -25.0 & 15.8 \\
\hline Ireland & 29.7 & 46.5 & -13.0 & 27.8 \\
\hline Italy & 390.8 & 422.2 & 6.5 & 13.5 \\
\hline Netherlands & 152.9 & 174.0 & 6.0 & 17.4 \\
\hline Portugal & 39.0 & 67.9 & -27.0 & 27.1 \\
\hline Spain & 203.8 & 302.6 & -15.0 & 22.5 \\
\hline Sweden & 50.6 & 54.0 & -4.0 & 2.5 \\
\hline Luxemburg & 10.6 & 11.6 & 28.0 & 34.2 \\
\hline Hungary & 68.5 & 62.2 & 6.0 & -3.5 \\
\hline Poland & 340.1 & 286.2 & 6.0 & -11.7 \\
\hline Cyprus & 4.5 & 8.1 & - & - \\
\hline Czech Rep. & 158.8 & 103.1 & 8.0 & -41.7 \\
\hline Malta & 2.5 & 3.3 & - & - \\
\hline Slovakia & 51.4 & 41.6 & 8.0 & -13.7 \\
\hline Slovenia & 10.9 & 14.0 & 8.0 & 28.4 \\
\hline Estonia & 36.6 & 14.2 & 8.0 & -137.1 \\
\hline Latvia & 16.9 & 8.3 & 8.0 & -87.3 \\
\hline Lithuania & 32.2 & 17.2 & 8.0 & -72.2 \\
\hline Bulgaria & 73.6 & 42.9 & 8.0 & -57.8 \\
\hline Romania & 168.6 & 90.3 & 8.0 & -71.8 \\
\hline Canada & 473.0 & 681.0 & 6.0 & 34.7 \\
\hline Japan & 990.0 & 1211.0 & 6.0 & 23.2 \\
\hline Russia & 2347.0 & 1732.0 & 0.0 & -35.5 \\
\hline Rest of FSU & 1452.0 & 1072.0 & 0.0 & -35.4 \\
\hline
\end{tabular}

Sources: European Commission (2003): European Energy and Transport Trends to 2030; US

Department of Energy (2005): International Energy Outlook; own calculations

Following the information in Table 3, the effective reduction requirements for EU-27 Member States range from more than 30 percent (here: Luxemburg) to negative "requirements" of more than 100 percent (here: Estonia). The aggregate EU-27 target for 2010 therefore turns out to be rather low vis-à-vis the BaU emissions level in 2010 as 
compared to rather substantial cutback requirements for other signatory OECD regions like Canada or Japan. In contrast, Russia stands out for a large negative effective reduction requirement. Unrestricted availability of the associated excess emissions permits from Russia (usually referred to as "hot air") to the international emissions market would therefore result in very low effective reduction requirements across all signatory Annex B regions.

The supply side situation is complemented by potential CDM project activities in Non-Annex B countries. Table 4 shows that within our project-based CDM dataset, China and India turn out as the key CDM suppliers accounting for more than 60 percent of the total emissions reduction potential in developing countries in 2010.

Table 4: CDM supply potential for whole cost range by Non-Annex B region

\begin{tabular}{|l|r|}
\hline \multicolumn{1}{|c|}{ Region } & \multicolumn{2}{c|}{$\begin{array}{c}\text { CDM supply potential } \\
\text { in 2010 (Mt CO } \mathbf{~}_{\mathbf{2}}\end{array}$} \\
\hline Brazil & 67.2 \\
\hline China including Hong Kong & 616.9 \\
\hline Central and South America & 195.9 \\
\hline India & 390.0 \\
\hline Rest of East South Asia & 213.1 \\
\hline South Africa & 37.7 \\
\hline Rest of World & 125.8 \\
\hline Total & $\mathbf{1 6 4 6 . 6}$ \\
\hline
\end{tabular}

Source: Wetzelaer et al. (2007)

Moreover, as Figure 2 shows, the aggregate CDM supply function (relating abatement potential to marginal abatement costs) suggests large abatement potential at zero or even "negative” costs. Moreover, the figure presents a CDM supply curve including transaction costs, as well as a curve including transaction costs and investment risk - both of which represent an upwardly shifted original supply curve. 


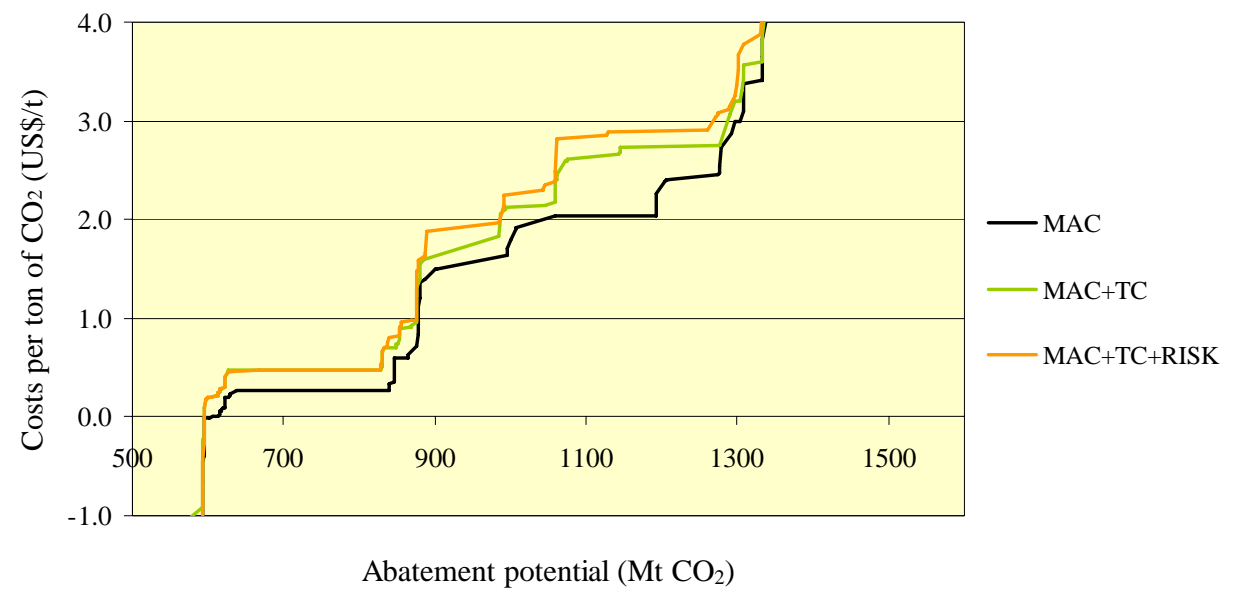

Figure 2: Excerpt of the aggregate marginal abatement cost (MAC) for the Non-Annex B region considering transaction costs (TC) and investment risk (RISK)

Source: Wetzelaer et al. (2007)

With unrestricted supply of "hot air" and CDM we would expect the price for emissions on competitive international markets to drop to zero since aggregate supply exceeds the effective demand. Regarding environmental effectiveness and compliance cost, policy-driven quantitative limits to "hot air" and CDM supply may become much more important than market-inherent barriers to CDM in terms of transaction costs and investment risks. Major institutional climate policy constraints include additionality (restriction to CDM projects which would not be undertaken without the provision of the flexibility mechanisms) and supplementarity (requiring that a minimum of abatement efforts should be undertaken domestically).

\section{Climate Policy Scenarios}

We design climate policy scenarios to address in particular the role of the CDM under the Kyoto Protocol. More specifically, we are interested in the quantitative effects of the CDM for the compliance cost of Annex B countries taking into account investment barriers (transaction costs and investment risks) as well as institutional climate policy constraints (additionality and supplementarity). 
The Marrakech Accords demand that domestic actions (as opposed to the use of the flexible mechanisms Emissions Trading, Joint Implementation and the Clean Development Mechanism) constitute a "significant element" of the efforts made by each Annex B Party to meet its target under the Kyoto Protocol (UNFCCC, 2002). While there is no explicit quantified proportion to be met through domestic action, Annex B Parties must provide information in their national communications under the Protocol to demonstrate that their use of the mechanisms is "supplemental to domestic action" to achieve their targets. One policyrelevant proposal to quantify a CER import limit as a supplementarity rule stems from the European Union, essentially stating that no more than 50 percent of an Annex B reduction commitment may be fulfilled by imports from the flexible mechanisms (Langrock and Sterk, 2004). We take the EU proposal as the reference for an optional supplementarity rule in our simulations.

Moreover, the Marrakech Accords define additionality for emission-reduction CDM projects by specifying that “a CDM project activity is additional if anthropogenic emissions of greenhouse gases by sources are reduced below those that would have occurred in the absence of the registered CDM project activity" (UNFCCC, 2002). We address this issue via financial additionality, implying that no investments that would have been undertaken in the absence of a CDM registration may be labeled as CDM (Dutschke and Michaelowa, 2006). In this case, emissions abatement options in Non-Annex B countries with negative abatement costs (so-called “No-Regret” options) are therefore not eligible for the CDM.

In our four central scenarios we combine alternative assumptions on CDM access, transaction costs, and investment risks (see Table 5).

Table 5: CDM characteristics of climate policy scenarios

\begin{tabular}{|l|c|c|c|}
\hline Scenario acronym & CDM access & $\begin{array}{c}\text { Transaction } \\
\text { costs }\end{array}$ & Investment risk \\
\hline ET & No & No & No \\
\hline ET_CDM & $Y e s$ & No & No \\
\hline ET_CDM_TC & $Y e s$ & $Y e s$ & No \\
\hline ET_CDM_TC_RISK & $Y e s$ & $Y e s$ & Yes \\
\hline
\end{tabular}

In order to reflect policy-relevant institutional policy regulations of permit supply from the CDM as well as "hot air", we investigate how the results for our central scenarios will change 
depending on additionality / supplementarity rules and a "hot air" limit (i.e. zero supply of excess permits by Russia).

\section{Simulation Results}

The impacts of climate policies are measured with respect to a hypothetical BaU scenario where no climate policy regime applies. ${ }^{4}$ Table 6 reports the prices for emissions permits across the central scenarios combined with alternative regulatory constraints on CDM supply and "hot air" access.

Table 6: International carbon permit price ( $\$ \mathrm{US}$ per ton of $\mathrm{CO}_{2}$ )

\begin{tabular}{|l|r|r|r|r|}
\hline \multicolumn{1}{|r|}{ Scenario } & ET & ET_CDM & $\begin{array}{r}\text { ET_CDM_ } \\
\text { TC }\end{array}$ & $\begin{array}{c}\text { ET_CDM_ } \\
\text { TC_RISK }\end{array}$ \\
\hline Hot Air & 3.19 & 0.00 & 0.20 & 0.23 \\
\hline No Hot Air & 12.62 & 0.71 & 0.81 & 2.98 \\
\hline $\begin{array}{l}\text { Additionality } \\
\text { (No Hot Air) }\end{array}$ & 12.62 & 2.47 & 2.75 & 2.80 \\
\hline $\begin{array}{l}\text { Supplementarity } \\
\text { (No Hot Air) }\end{array}$ & 12.62 & see Table 7 & see Table 7 & see Table 7 \\
\hline
\end{tabular}

We see that the $\mathrm{CO}_{2}$ permit price resulting from international emissions trading in the absence of the CDM but with full "hot air" supply amounts to roughly 3 US\$. This result can be traced back to the rather low effective emissions reduction requirements of Annex B countries combined with large supplies of excess permits by Russia. If we fully ban "hot air" supply, the international permit price quadruples: Marginal abatement costs across Annex B countries increase drastically as larger parts of emissions reduction requirements can no longer be covered by pure paper trade but require actual abatement. In a policy regime with unlimited access of Annex B regions to CDM and unlimited supply of "hot air" the $\mathrm{CO}_{2}$ value falls to zero as we simultaneously abstract from CDM transaction costs and investment risks: "Hot air” supply by Russia together with large CDM inflows at zero cost induce a situation of excess supply on the international market for emissions permits. When we consider CDM 
transaction costs (in terms of an absolute price premium), the permit value slightly increases to 0.2 US\$. Additional investment risks of CDM projects (in terms of a relative price premium) lead to a further - but rather small - increase of the $\mathrm{CO}_{2}$ value. In the absence of "hot air" supply but with unlimited CDM access, we still obtain a permit price of less than one dollar (0.71 US\$). Transaction cost and investment risk premia again have only very small impacts on the effective carbon price.

An additionality rule restricts the number of projects eligible for the CDM, aiming at filtering out so-called "No-Regret" options. ${ }^{5}$ As a consequence, the CDM options available for Annex B countries are reduced substantially. Table 6 indicates that additionality implies a substantial increase in the $\mathrm{CO}_{2}$ value: The permit price rises to roughly 2.5 US\$. As in the case of unrestricted CDM projects, transaction costs and investment risk cause only very small price increases.

Under a supplementarity rule, the resulting regional marginal abatement costs are composed of the international permit price and region-specific shadow prices of the implicit permit import quota that generates the required domestic emissions reductions. ${ }^{6}$ Complementing the information provided in Table 6, Table 7 reports marginal abatement costs across model regions under a supplementarity criterion (and excluding “hot air” supply). A supplementarity rule restricts CDM permit imports and thereby exerts a downward pressure on the supply-side value of CDM credits (like an import tariff). On the other hand, the import quota drives up the effective marginal abatement cost at the regional level since Annex B countries must achieve a minimum of (in our case) 50 percent of the effective national reduction requirement through domestic action. Transaction costs and investment risk have only negligible impacts on these marginal costs where the major cost component stems from domestic action and is unaffected from barriers to project-based emissions abatement.

\footnotetext{
${ }^{4}$ Note that the listing of two digits should not pretend any prognostic precision or accuracy but simply helps to highlight (potentially small) differences across different scenarios.

${ }^{5}$ The permanence of such options, implying negative marginal abatement costs, may stem from implicit investment barriers such as incomplete information.

${ }^{6}$ If regional marginal abatement costs for the required domestic abatement exceed the international permit price, the regional shadow price is given by the difference of the two values. Otherwise, the shadow price is zero.
} 
Table 7: Supplementarity (No Hot Air) - marginal abatement costs ( $\$ \mathrm{US} /$ ton of $\mathrm{CO}_{2}$ )

\begin{tabular}{|c|c|c|c|}
\hline Region & $E T_{-} C D M$ & $\underset{T C}{E T_{C} C D M_{-}}$ & $\begin{array}{c}E T_{-} C D M_{-} \\
T C_{-} R I S K\end{array}$ \\
\hline Austria & 29.25 & 29.28 & 29.29 \\
\hline Belgium & 27.72 & 27.73 & 27.73 \\
\hline Denmark & 3.77 & 3.78 & 3.78 \\
\hline Finland & 0.27 & 0.47 & 0.48 \\
\hline France & 16.89 & 16.89 & 16.89 \\
\hline Germany & 3.53 & 3.53 & 3.53 \\
\hline United Kingdom & 5.33 & 5.34 & 5.34 \\
\hline Greece & 3.65 & 3.66 & 3.66 \\
\hline Ireland & 16.08 & 16.08 & 16.08 \\
\hline Italy & 14.19 & 14.20 & 14.20 \\
\hline Netherlands & 13.95 & 13.95 & 13.95 \\
\hline Portugal & 16.98 & 17.00 & 17.00 \\
\hline Spain & 19.52 & 19.52 & 19.52 \\
\hline Sweden & 4.47 & 4.48 & 4.48 \\
\hline Hungary & 1.07 & 1.08 & 1.08 \\
\hline Poland & 0.27 & 0.47 & 0.48 \\
\hline Czech Republic & 0.27 & 0.47 & 0.48 \\
\hline Slovakia & 0.27 & 0.47 & 0.48 \\
\hline Bulgaria & 0.27 & 0.47 & 0.48 \\
\hline Romania & 0.27 & 0.47 & 0.48 \\
\hline Rest of EU & 28.13 & 28.15 & 28.15 \\
\hline Baltic States & 0.27 & 0.47 & 0.48 \\
\hline Canada & 0.27 & 0.47 & 0.48 \\
\hline Japan & 0.27 & 0.47 & 0.48 \\
\hline Russia & 0.00 & 0.00 & 0.00 \\
\hline Rest of FSU & 0.27 & 0.47 & 0.48 \\
\hline
\end{tabular}

Table 8 summarizes the emissions reductions from Business-as-Usual (BaU) emissions levels across our climate policy scenarios. ${ }^{7}$

\footnotetext{
${ }^{7}$ Note that in our reporting of simulation results, in the following we concentrate on Russia as the central supplier of excess emissions permits.
} 
Table 8: Emissions reduction by region (\% vs. BAU)

\begin{tabular}{|c|c|c|c|c|}
\hline Region & $E T$ & $E T_{-} C D M$ & $\begin{array}{c}E T_{-} C D M_{-} \\
T C\end{array}$ & $\begin{array}{c}E T_{-} C D M_{-} \\
T C_{-} R I S K\end{array}$ \\
\hline \multicolumn{5}{|c|}{ Hot Air } \\
\hline$E U-27$ & -4.50 & 0.00 & -0.40 & -0.40 \\
\hline Canada & -2.90 & 0.00 & -0.20 & -0.20 \\
\hline Japan & -4.70 & 0.00 & -0.30 & -0.40 \\
\hline Russia & -3.00 & 0.00 & -0.20 & -0.20 \\
\hline \multicolumn{5}{|c|}{ No Hot Air } \\
\hline$E U-27$ & -12.50 & -1.20 & -1.30 & -1.60 \\
\hline Canada & -11.70 & -0.60 & -0.70 & -0.90 \\
\hline Japan & -12.70 & -1.20 & -1.30 & -1.60 \\
\hline Russia & 0.50 & 0.00 & 0.00 & 0.00 \\
\hline \multicolumn{5}{|c|}{ Additionality (No Hot Air) } \\
\hline$E U-27$ & -12.50 & -3.70 & -4.00 & -4.10 \\
\hline Canada & -11.70 & -2.20 & -2.40 & -2.50 \\
\hline Japan & -12.70 & -3.80 & -4.10 & -4.20 \\
\hline Russia & 0.50 & 0.10 & 0.10 & 0.10 \\
\hline \multicolumn{5}{|c|}{ Supplementarity (No Hot Air) } \\
\hline$E U-27$ & -12.50 & -6.30 & -6.40 & -6.40 \\
\hline Canada & -11.70 & -0.20 & -0.40 & -0.40 \\
\hline Japan & -12.70 & -0.50 & -0.80 & -0.80 \\
\hline Russia & 0.50 & 0.10 & 0.10 & 0.10 \\
\hline
\end{tabular}

In general, the magnitude of emissions reductions reflects - ceteris paribus - the level of the marginal abatement cost: The higher the marginal abatement cost, the higher is the associated domestic emissions reduction. In this vein, Table 8 reports an almost threefold emissions abatement in EU-27 triggered by the limitation of "hot air" supply and the associated increase in the international permit price for the base scenario "ET" (as we compare variants "hot air" and no "hot air"). CDM supply induces very low emissions reduction levels by EU-27 due to larger permit imports. Both CDM regulations - additionality as well as supplementarity increase domestic emissions abatement by EU-27 regions substantially. While the abatement effects for non-EU countries with effective emissions reduction requirements are comparable to the EU effects for alternative "hot air" specifications and an additionality rule, a supplementarity criterion does not increase domestic abatement of these countries substantially. Obviously, under unlimited CDM Japan and Canada have not yet reached the respective import thresholds implied by a supplementarity rule. 
Table 9 summarizes economy-wide adjustment cost of emissions regulation across regions. Theses inframarginal costs can be expressed as a change in the Hicksian equivalent variation (HEV) measuring the change in real income which is necessary to make the economy under regulation as well off as under BaU. A positive HEV thus indicates net economic gains whereas a negative HEV signals an economic loss. ${ }^{8}$

Table 9: Welfare impacts by region (\% change HEV)

\begin{tabular}{|c|c|c|c|c|}
\hline Region & $E T$ & $E T \_C D M$ & $\underset{T C}{E T_{C} C D M_{-}}$ & $\begin{array}{c}E T_{-} C D M \\
T C_{-} R I S K\end{array}$ \\
\hline \multicolumn{5}{|c|}{ Hot Air } \\
\hline$E U-27$ & -0.009 & 0.000 & -0.001 & -0.001 \\
\hline Canada & -0.139 & 0.000 & -0.009 & -0.010 \\
\hline Japan & -0.018 & 0.000 & -0.001 & -0.001 \\
\hline Russia & 0.519 & 0.000 & 0.032 & 0.036 \\
\hline \multicolumn{5}{|c|}{ No Hot Air } \\
\hline$E U-27$ & -0.001 & -0.002 & -0.003 & -0.003 \\
\hline Canada & -0.489 & -0.032 & -0.036 & -0.044 \\
\hline Japan & -0.054 & -0.004 & -0.005 & -0.006 \\
\hline Russia & -0.046 & -0.003 & -0.003 & -0.004 \\
\hline \multicolumn{5}{|c|}{ Additionality (No Hot Air) } \\
\hline$E U-27$ & -0.001 & -0.007 & -0.007 & -0.007 \\
\hline Canada & -0.489 & -0.108 & -0.120 & -0.122 \\
\hline Japan & -0.054 & -0.014 & -0.016 & -0.016 \\
\hline Russia & -0.046 & -0.010 & -0.011 & -0.011 \\
\hline \multicolumn{5}{|c|}{ Supplementarity (No Hot Air) } \\
\hline$E U-27$ & -0.001 & -0.014 & -0.015 & -0.015 \\
\hline Canada & -0.489 & -0.016 & -0.025 & -0.026 \\
\hline Japan & -0.054 & -0.002 & -0.004 & -0.004 \\
\hline Russia & -0.046 & -0.014 & -0.014 & -0.014 \\
\hline
\end{tabular}

We observe that the welfare impacts for the EU-27 from emissions reduction requirements under the Kyoto Protocol are in general very small. Allowing for CDM, non-negligible welfare costs are only present in the cases of additionality and supplementarity regulations

\footnotetext{
${ }^{8}$ Note that we pursue a cost-effectiveness analysis that quantifies adjustment costs of environmental regulation as compared to an unconstrained business-as-usual situation. We thereby deliberately neglect the economic benefits from controlling global warming. Again the listing of three digits should not pretend any prognostic precision or accuracy but simply helps to highlight (potentially small) differences across different scenarios.
} 
which restrict CDM supply and demand, thereby increasing adjustment costs. Welfare costs for the EU-27 are highest in a supplementarity setting where "hot air" is simultaneously restricted. Transaction costs and CDM investment risk hardly affect the economy-wide adjustment cost of emissions constraints.

As a supplier of excess emissions permits Russia is largely benefiting from a climate policy regime where "hot air" is unrestricted, but faces welfare costs in the case of a ban of its respective supplies. While the welfare effects for non-EU countries with effective emissions reduction requirements are comparable to the EU effects regarding "hot air" and the CDM, for Japan and Canada the regulations of project-based crediting generate reversed impacts: As under unlimited CDM these countries have not yet reached the respective import thresholds implied by a supplementarity rule, it is the additionality regulation that naturally implies a higher level of welfare costs for the respective economies.

\section{Conclusions}

In this paper we have investigated the macroeconomic impacts of the Clean Development Mechanism under the Kyoto Protocol. For our quantitative analysis we have employed a large-scale computable general equilibrium model of international trade and energy use that reflects the project-based character of the CDM by integrating explicit bottom-up CDM supply curves. We have examined the implications of CDM transaction costs and investment risk as well as the consequences of explicit policy constraints on CDM supply (in terms of supplementarity and additionality rules) and the availability of "hot air".

We find that the CDM is an important flexibility mechanism to achieve the Kyoto targets at low cost - in particular, if Annex B countries intend to exclude "hot air" from international emissions trading. The main driver of this result is the availability of large amounts of CDM credits at very low cost. As cost determinants, transaction costs and investment risk of project-based emissions crediting play only an inferior role. Much more relevant for the overall compliance costs are policy constraints to the use of the CDM as reflected by additionality or supplementarity criteria, both inducing higher levels of domestic emissions abatement. Project-based emissions crediting clearly should generate emissions reductions below those that would have occurred in the absence of the CDM - from a pure costeffectiveness perspective, our simulation analysis warrants however caution against restrictive regulations of CDM access by means of a supplementarity rule. 


\section{References}

Armington, P. S. (1969): “A Theory of Demand for Producers Distinguished by Place of Production”, IMF Staff Papers 16, 159-178.

Böhringer, C. (2000): “Cooling Down Hot Air - A Global CGE Analysis of Post-Kyoto Carbon Abatement Strategies”, Energy Policy 28, 779-789, 2000.

Böhringer, C. (2002): “Climate Politics From Kyoto to Bonn: From Little to Nothing?”, The Energy Journal 23 (2), 51-71, 2002.

Böhringer, C., Jensen, J., and T.F. Rutherford (2000): "Energy Market Projections and Differentiated Carbon Abatement in the European Union”, in: C. Carraro (ed.): Efficiency and Equity of Climate Change Policy, Kluwer, Amsterdam, 199-220.

Böhringer, C. and A. Löschel (2002): "Risk and Uncertainty in Project-based Emissions Crediting”, in: Van Ierland, E.C., Weikard, H.P. and J. Wesseler (eds.): Risk and Uncertainty in Environmental and Resource Economics, Conference Proceedings, 5-7 June 2002, Wageningen University, Wageningen.

Böhringer, C. and C. Vogt (2003): "Economic and Environmental Impacts of the Kyoto Protocol”, Canadian Journal of Economics 36, 475-494.

Böhringer, C. and C. Vogt (2004): The Dismantling of a Breakthrough: The Kyoto Protocol Just Symbolic Policy, European Journal of Political Economy, 20(3), 597-617.

Conrad, K. (1999): “Computable General Equilibrium Models for Environmental Economics and Policy Analysis”, in J. C. J. M. van den Bergh (ed.): Handbook of Environmental and Resource Economics, Edward Elgar, Cheltenham, 1061-1087.

Conrad, K. (2001): “Computable General Equilibrium Models in Environmental and Resource Economics”, in T. Tietenberg and H. Folmer (eds.): International Yearbook of Environmental and Resource Economics 2002/2003, Edward Elgar, Cheltenham, 66-114.

Dimaranan, B. and R.A. McDougall (2006): Global Trade, Assistance and Production: The GTAP 6 Data Base, Center for Global Trade Analysis, Purdue University, West Lafayette, IN.

Dutschke, M. and A. Michaelowa (2006): "Development assistance and the CDM - how to interpret 'financial additionality”, Environment and development economics 11 (2), 235246. 
EU (2003): Directive Establishing a Scheme for Greenhouse Gas Emissions Allowance Trading within the Community and Amending Council Directive 96/61/EC. European Commission, Brussels. Available at: $\underline{\text { http://eur- }}$ ex.europa.eu/LexUriServ/site/en/oj/2003/1_275/1_27520031025en00320046.pdf

EU (2004): Directive 2004/101/EC, amending Directive 2003/87/EC establishing a scheme for greenhouse gas emissions allowance trading within the Community, in respect of the Kyoto Protocol's project mechanisms. European Comission, Brussels. Available at: http://europa.eu.int/comm/environment/climat/emission/pdf/dir_2004_101_en.pdf

EU (2005): Further guidance on allocation plans for the 2008 to 2012 trading period of the EU Emissions Trading Scheme, COM(2005) 703 final. European Commission, Brussels. Available at: http://europa.eu.int/comm/environment/climat/pdf/nap_2_guidance_en.pdf

European Commission (2003): European Energy and Transport Trends to 2030.

European Environment Agency (2005): Greenhouse gas emissions trends and projections in Europe 2005. EEA Report No 8/2005, Copenhagen.

Jotzo, F. and A. Michaelowa (2002): "Estimating the CDM market under the Marrakech Accords”, Climate Policy 2, 179-196.

Kallbekken, S., Flottorp, L.S. and N. Rive (2006): "Why the CDM will reduce carbon leakage”, paper presented at the 3rd World Congress of Environmental and Resource Economists in Kyoto, 3-7 July 2006.

Langrock, T and W. Sterk (2004): “The Supplementarity Challenge: CDM, JI \& EU Emissions Trading”. Policy Paper 1/2004, Wuppertal Institute for Climate, Environment and Energy.

Michaelowa, A. and F. Jotzo (2005): "Transaction costs, institutional rigidities and the size of the clean development mechanism”, Energy policy 33 (4), 511-523.

Oleschak, R. and U. Springer (2007): "Measuring the Risk of Investments in Climate Change Mitigation: A Composite Indicator”. Deliverable report, Technology Transfer and Investment Risk in International Emissions Trading (TETRIS).

UNFCCC (1997): Kyoto Protocol to the United Nations Framework Convention on Climate Change, United Nations Framework Convention on Climate Change, FCCC/CP/L.7/Add1, Kyoto. 
UNFCCC (2002): Report of the Conference of the Parties on its seventh session, held at Marrakesh from 29 October to 10 November 2001. Part one: Proceedings.. Available at: http://unfccc.int/resource/docs/cop7/13.pdf

US Department of Energy (2005): International Energy Outlook, Energy Information Administration.

Weyant, J.P. and J. Hill (1999): "Introduction and Overview”, The Energy Journal, special issue: The costs of the Kyoto Protocol: a multi-model evaluation, vii-xliv.

Wetzelaer, B.J.H.W., van der Linden, N.H., de Coninck, H.C. and H. Groenenberg (2007): "Marginal Abatement Cost curves for the non-Annex I region: Assessment of potential and cost of CDM options”. Deliverable report, Technology Transfer and Investment Risk in International Emissions Trading (TETRIS).

Youngman, R., Forrister, D., Rosenzweig, R., Wetzelaer, B.J.H.W., van der Linden, N.H., de Coninck, H.C., Haake, F., Schmidt, J., Lee, J. and A. Blachowicz (2007): “Technology Transfer and the Kyoto Protocol's Flexible Mechanisms”. Deliverable report, Technology Transfer and Investment Risk in International Emissions Trading (TETRIS). 